\title{
El inicio de la problemática ontológica en el comienzo de la filosofía ${ }^{1}$ The beginning of ontological problematic on the birth of philosophy.
}

\author{
IÑAKI MARIETA
}

Universidad de La Laguna

\begin{abstract}
RESUMEN. En el comienzo de la filosofía la problemática ontológica que hunde sus raíces en la propia lengua griega y más precisamente en el participio presente del verbo ser, va a cobrar una importancia decisiva para el desarrollo del pensamiento occidental. Esta marca lingüística, exclusiva de la lengua griega, justifica el hecho de que la filosofía sea función de la diferencia ontológica y que para aquella, ser y pensar sean lo mismo. Porque el ser sólo puede ser pensado desde la aprioridad que gnoseológicamente impone su estatuto transcendental.
\end{abstract}

Palabras clave: diferencia ontológica; lengua griega; ser; filosofía; a priori; transcendental.
ABSTRACT. On the birth of philosophy, the ontological problematic which dips its roots into the Greek language and precisely into the present participle of the verb to be, is going to get a vital importance for the development of the occidental thinking. This linguistic mark, exclusively of the Greek language justifies the fact that philosophy is the function of the ontologic difference and for that one, being and thinking is the same. Because being can only be thought from the apriority that gnoseologically imposes its transcendental statute.

Key words: ontologic difference; Greek language; being; philosophy; a priory.

1 "Distinguimos, con respecto al pensar temprano en occidente con los griegos, entre comienzo e inicio (Beginn und Anfang). El comienzo menciona el aparecer de este pensar en un determinado "tiempo" (...) El "comienzo" concierne al surgimiento y a la inauguración del pensar. El "inicio" es lo que, en este pensar temprano, hay que pensar y lo que es pensado. (...) Llamamos inicio a lo que es pensado en el pensar del pensador. Esto quiere decir, por tanto, ahora: el ser es el inicio (Das Sein ist der Anfang)" M. Heidegger, Parménides, Akal, Madrid, pp. 12-13. 
"Ce ne serait donc pas un simple hasard si les Grecs, ces poètes du destin, (...) ont pu être caractérisés comme $\varphi \imath \lambda o \mu \varepsilon ́ \tau o \chi 01:$ amis du participe"

\section{En el origen de la filosofía: el asombro ante qué}

Es Platón, el primero, en el Teeteto, y después Aristóteles, en el primer libro de los Metafisica, quienes en la literatura filosófica griega antigua, ponen el $\theta \alpha v \mu \alpha ́ \zeta \varepsilon i v$ en el origen mismo de la filosofía. Y nada parece más natural al arranque del filosofar que el que éste ocurra por un quedarse admirado, asombrado, estupefacto. Pero, ¿ante qué? Platón no lo dice. Sólo afirma a través de Sócrates y para con-

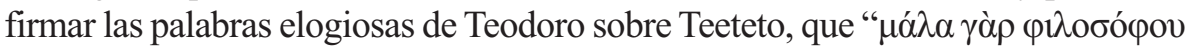

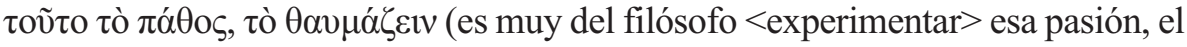

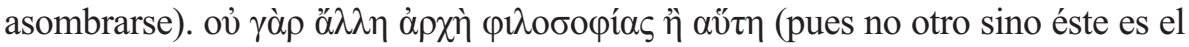
origen de la filosofía)." 2 Aunque el texto de Platón no dota de contenido al hecho de quedarse estupefacto, sí contiene una información fundamental para entender la conexión entre el filósofo y el hecho de quedarse asombrado. Pues siendo como

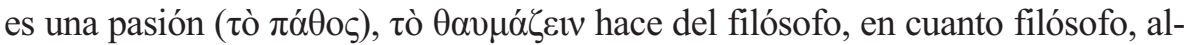
guien arrebatado por el asombro, alguien esclavo, diríamos, de ese particular fenómeno que es el quedar estupefacto. Pero, ¿ante qué? Sólo sabemos que esta situación es el origen mismo del filosofar, y en cuanto tal "die Herkunft seines

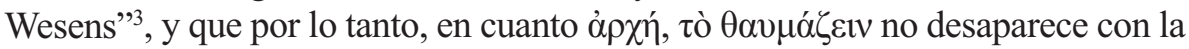
puesta en marcha de la actividad filosófica sino que se mantiene activo a lo largo de toda la vida de quien filosofa, y con su decaimiento desaparece el filosofar mismo ${ }^{4}$. Sólo puede haber pues un filósofo estupefacto. De modo que "el asombro sostiene y domina la filosofía desde el principio hasta el final.".5

Naturalmente cualquiera podría decir que los motivos de asombro para el humano son infinitos. Cierto que como una forma de hablar. Pero no le faltaría razón. Todo puede ser motivo de asombro ${ }^{6}$. Pero entonces, porqué no todos

${ }^{2}$ Teeteto, 155 d1-4 (la trad. es mía).

3 "la fuente de su esencia." M. Heidegger, El origen de la obra de arte, en Caminos del bosque, Alianza, Madrid, 1998, p. 11.

4 "El comienzo del pensamiento occidental no es lo mismo que el principio. Pero ese comienzo sí que es una ocultación del principio e incluso una ocultación ineludible. Si así están las cosas, el olvido se muestra bajo otra luz. El principio se esconde en el comienzo" M. Heidegger, ¿Qué significa pensar?, Trotta, Madrid, 2005, p.137.

${ }^{5}$ M. Heidegger, ¿Qué es la filosofía?, Herder, Barcelona, 2004, p. 59

6 “ (...) lo que nos parece natural -escribe Heidegger- es sólo, presumiblemente, lo habitual de una larga costumbre que se ha olvidado de lo inhabitual de donde surgió. Sin embargo, eso inhabitual causó en otros tiempos la sorpresa de los hombres y condujo el pensar al asombro" op. cit., p. 16. 
somos filósofos. O acaso lo seamos y no lo sabemos. ¿Quién no se ha admirado alguna vez de algo? ¿La filosofía consistiría entonces en que cualquiera se admirase de cualquier cosa durante un tiempo? ¿Y una vez satisfecha la admiración? La condición patética del quedar bajo el efecto del estupor hace que quien la padece no pueda decidir acerca de su término, sino que es la propia condición la que nos tiene cogidos y decide acerca de su final. Esta situación no parece muy moderna, en el sentido de que para la modernidad no puede haber otro agente de decisión que el propio individuo. De todo decidimos nosotros, o así nos lo representamos. Y no lo es porque lo que reproduce esa situación no puede ser moderno en la medida en que es griego: cronológicamente premoderno pero filosóficamente antimoderno. Lo que ocurre en la Grecia antigua en relación con el individuo y su pasión filosófica es algo que la modernidad, salvo raras excepciones, y no digamos la pos-modernidad, no están en condiciones de entender. La falta de respuesta definitiva tanto en clave soteriológico-transcendental como en clave epistemológica y tecno-científica, hacen de la filosofía griega en lo que tiene de más genuina pasión, a saber, de más griega, algo difícilmente recuperable para las coordenadas instrumentales en las que se ha desarrollado la modernidad. Pero no todo está perdido. Nos queda por responder al "ante qué" queda estupefacto el filósofo en cuanto filósofo.

Una respuesta que Platón no da en este comienzo del Teeteto ${ }^{7}$; confrontándonos en la continuación del diálogo a un juego etimológico que surte el efecto de un enigma. Pues escribe, "el que dijo que Iris ('I $\mathrm{s} ı v$ ) era hija de Taumante $(\Theta \alpha v ́ \mu \alpha v \tau o \varsigma)$ parece que no trazó erróneamente su genealogía" ${ }^{\text {. Tau- }}$ mante parece tener relación etimológica con $\theta \alpha \tilde{v} \mu \alpha$ (lo que asombra, admira o deja estupefacto) y siendo como pretende Platón, padre de Iris, la cual estando

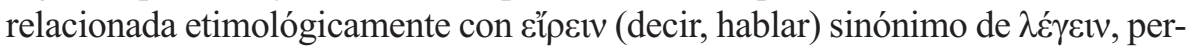
sonifica la actividad dialéctica y filosófica, la relación paterno filial entre ambas divinidades justificaría la conceptual. Con lo cual, como genealógicamente queda demostrado, la Filosofía (Iris) es hija de la Admiración (Taumante).

Aun cuando este pequeño ejercicio etimológico no constituye prueba filosófica de nada, sí muestra un $\pi \alpha ́ \theta$ o $\varsigma$ genuinamente griego en relación con la ge-

${ }^{7}$ En el Sofista (244a), diálogo posterior al Teeteto, Platón identifica la problemática filosófica en su dimensión ontológica, con la aporética que plantea la cuestión del ser, en un texto emblemático para la problemática ontológica contemporánea pues Heidegger lo pone como epígrafe a Ser y tiempo: "Entonces, puesto que nosotros hemos dado con una dificultad, explicadnos vosotros suficientemente qué es lo que queréis significar cuando pronunciáis la palabra ser ( $\tau$ í $\pi \mathrm{o} \tau \varepsilon$

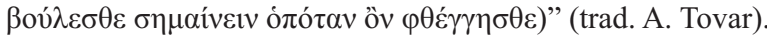

${ }^{8}$ Teeteto, 155d 4-5, Gredos, Madrid, 1988. 
nealogía que en este caso Platón pretende elevar a razón genealógica, y que desde los orígenes del pensamiento griego llega hasta la contemporaneidad filosófica. Pues, según Deleuze, "Nietzsche crea el nuevo concepto de genealogía. El filósofo es un geneaólogo, no un juez de tribunal a la manera de Kant, ni un mecánico al modo utilitarista. El filósofo es Hesíodo." Seguro que Platón no tenía tan clara la afirmación del filósofo francés relativa a Hesíodo, como tampoco Heráclito, quien lo acusa de "plurisciente" ( $\pi \circ \lambda \nu \mu \alpha \theta \eta \dot{\varsigma} \varsigma)$; lo contrario de lo que considera el Efesio, en traducción de A. García Calvo, "tener seso" (vóov $\left.\varepsilon_{\chi} \measuredangle i v\right)^{10}$. Prueba, todo ello, de que la razón genealógica atraviesa el pensamiento griego con una fuerza que trasciende la voluntad racional de los propios filósofos, en este caso de Platón, imponiéndose como un principio de conocimiento que enlaza con una sabiduría arcaica que la filosofía rechazará como pre-argumental. Pues de lo que se trata en filosofía, de Platón en adelante, es de dar razón $(\lambda o ́ \text { ov } \delta i ́ \delta o v \alpha \imath)^{11}$, de argumentar, trayendo a la discusión elementos conceptuales que justifiquen la pretensión lógica a la verdad de la hipótesis que se está tratando. En ese sentido, la argumentación etimológica con pretensiones de fundamentar una razón genealógica se demuestra a lo largo de los diálogos de Platón, y especialmente en Crátilo, como un medio añadido y muy problemático, a lo que constituye el auténtico argumentar filosófico. Pues este último aporta razones allí donde la etimología propone conexiones lingüísticas que sólo desde una compresión naturalista del significado cobran un sentido, sujeto siempre a una experiencia poética del mundo en la que el significante revela la esencia de la cosa idéntica al significado del término que la nombra ${ }^{12}$. La filosofía en cuanto tal, y Platón como su primer representante ${ }^{13}$, parte de una comprensión convencional de las relaciones de significación desde las que se dota de sentido a la actividad lingüística. Y es precisamente esta posición, basada en el postulado convencionalista consecuencia a su vez de una no com-

${ }^{9}$ G. Deleuze, Nietzsche y la filosofía, Anagrama, Barcelona, 1986, p. 9.

10 "Ello es, en fin, que plurisciencia no ensaña a tener seso: que se lo habría enseñado a Hesíodo y también a Pitágoras, y asimismo a Jenófanes y a Hecateo" Heráclito, D-K, B 22 [40]; "Pero maestro de las más enseñanzas $<_{0}$ de los más>, Hesíodo: ése entienden que es el que más cosas sabe, uno que no conocía 'día y noche': que es que son una sola cosa" D-K, B 22 [57], en A. García Calvo, Razón común, Lucina, Madrid, 1985, p. 82 y 98.

${ }^{11}$ Cf. Rep., VII 534 b 3; M. Vegetti, Platón, Gredos, Madrid, 2012, pp. 202-203.

${ }^{12} \mathrm{La}$ riqueza y problemática filosófica de esta cuestión queda recogida de manera ejemplar en el Crátilo, donde la discusión acerca de la rectitud de los nombres propios trasciende su ámbito específico para plantear la confrontación convencionalismo (Hermógenes)/naturalismo (Crátilo) que articulará históricamente el debate acerca de la naturaleza del lenguaje.

13 "La "filosofía", que comienza sólo a partir de Platón, tiene desde ese momento el carácter de lo que más tarde se llamará "metafísica"." M. Heidegger, La doctrina platónica de la verdad, en Hitos, Alianza, Madrid, 2000, p. 196. 
prensión acerca de la pv́ఠıৎ (arranque de la metafísica), la que justifica su demanda de razones para alcanzar la verdad frente a la poesía que funda su actividad creativa en una compresión de la significación como revelación a través del significante, de lo que las cosas son. Es lógico pues que desde el primer momento en que surge la filosofía; filosofía y poesía chocasen sin posibilidad de llegar a un acuerdo, pues lo que las separa y distingue son dos concepciones y experiencias del fenómeno lingüístico, en su sentido lógico, irreductible la una a la otra.

Precisamente, la filosofía surge por el alejamiento que se produce en parte de la experiencia poética en relación a la comprensión del acto significante que constituye el lenguaje como revelación ${ }^{14}$. La filosofía no cree que en la palabra se revele de modo natural la verdad de las cosas o lo que es lo mismo, que el significante revele en el significado lo que la cosa nombrada es, y que para alcanzarlo baste con establecer conexiones etimológicas que de modo natural dejarán que emerja el sentido propio de lo que es. La filosofía, en cuanto filosofía, se inicia con la sospecha acerca de la capacidad reveladora del lenguaje y por eso le pide razones.

"La filosofía griega — escribe Gadamer-, se inicia precisamente con el conocimiento de que la palabra es sólo nombre, esto es, que no representa al verdadero ser. Esta es la irrupción del preguntar filosófico dentro del dominio antes indiscutido del nombre. Fe en la palabra y dudas respecto a la palabra son lo que caracteriza la situación del problema bajo la cual consideraba el pensamiento de la ilustración griega la relación entre palabra y cosa." 15

En segundo lugar, es Aristóteles quien en el capítulo segundo del primer libro de los Metafísica, hace del asombro el arranque del filosofar. En este caso, el contenido del texto nos acerca al "ante qué" de la situación originaria de todo filosofar de un modo explícito. En el contexto de la discusión acerca de las características de la sabiduría, Aristóteles afirma, "que no se trata de una ciencia

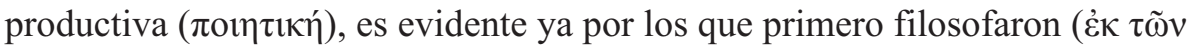
$\pi \rho \omega ́ \tau \omega v ~ \varphi \imath \lambda о \sigma o \varphi \eta \sigma \alpha ́ v \tau \omega v)$. Pues los hombres comienzan y comenzaron siem-

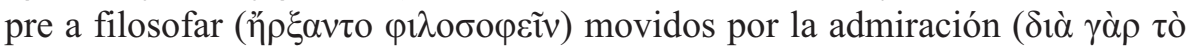

\footnotetext{
${ }^{14}$ A este respecto, J. Beaufret escribe: “Comprenons bien ici l'extraordinaire différence qui sépare la nouvelle parole, celle d'Héraclite et de Parménide, de l'antique parole qui, bien avant eux, fut celle des poètes, celle surtout de cet initiateur de la parole poétique que fut Homère. Nous pouvons dire que la nouvelle parole s'attache expressément à dire ce à l'intérieur de quoi seulement les poètes voyaient ce qu'ils nommaient, mais sans jamais le dire comme tel. Homère voit

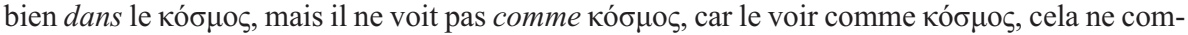
mence qu'avec Héraclite ou avec Parménide (...) " La naissance de la philosophie, en Dialogue avec Heidegger *, Minuit, Paris, 1973, pp. 27-28.

${ }^{15}$ H-G. Gadamer, Verdad y método I, Sígueme, Salamanca, 2005, p. 487.
} 
$\theta \alpha v \mu \alpha ́ \zeta \varepsilon ı v)$; al principio, admirados ante los fenómenos sorprendentes más co-

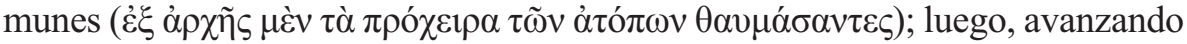
poco a poco y planteándose problemas mayores, como los cambios de la luna y los relativos al sol y a las estrellas, y la generación del universo."16

$\mathrm{Si}$ en ambos casos el origen del filosofar radica en la admiración, en éste, Aristóteles nos dice expresamente el "ante qué" de dicha admiración. De una manera sorprendentemente empírica Aristóteles supone que lo primero que movió al asombro y por lo tanto al filosofar, fueron las cosas más comunes ( $\tau \grave{\alpha}$ $\pi \rho o ́ \chi \varepsilon i \rho \alpha)^{1}$, literalmente, lo que tenemos a mano, lo que tenemos al alcance de la mano, y que puede ser la mano, en cuanto empezamos a tomar conciencia de la mano misma y de las capacidades que puede desarrollar. Sin duda que la mano es de lo más común para el humano que somos y a la vez un elemento claramente diferenciador en relación al resto de seres vivos. Admirarse de las posibilidades que brinda la mano supone un momento de conciencia que no lo funda el reconocimiento de la mano y de lo a la mano ( $\tau \alpha$ d $\pi \rho o ́ \chi \varepsilon i \rho \alpha)$, sino que más bien lo supone ${ }^{1}$. Así, si en el origen del filosofar está según Aristóteles, un asombrarse acerca de las cosas más comunes para después ir creciendo en dificultad aquello que nos causa estupefacción, lo que falta por determinar no es el grado de dificultad del que se parte o al que se llega sino la categoría misma de lo admirable, o incluso diríamos, la admirabilidad que hace de lo admirable, incluso de lo más común, el origen del filosofar, es decir, la búsqueda del saber por el puro conocimiento que entraña y no por alguna utilidad ${ }^{19}$.

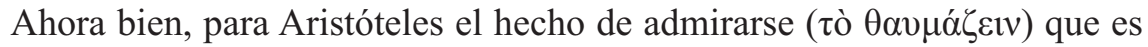
tanto como una aporía, conlleva la negatividad que supone quien reconoce su ignorancia en relación con algo. Pues sin ese momento negativo que es el admirarse como función de la ignorancia, no se pondría en marcha la conciencia que nos separa de la naturaleza en la que el resto de seres vivos viven sin sentir el asombro que a nosotros, humanos, nos determina. La negatividad que con-

${ }^{16}$ Met., A 2, 982b 11-14, Gredos, Madrid, 1982.

${ }^{17}$ Ver nota 3. Ver R. Brague, La fenomenología como vía de acceso al mundo griego. Nota sobre la crítica de la Vorhandenheit como modelo ontológico en la lectura heideggeriana de Aristóteles, en Revista de Filosofia, $3^{\mathrm{a}}$ época, vol. IV, (1991), nº . 6, ed. Complutense, Madrid, p. 426.

18 “ “... la esencia de la mano no podrá definirse jamás como un órgano de prensión corporal, o explicarse desde esa dimensión. También los monos, por ejemplo, tienen órganos de prensión y, sin embargo, carecen de manos. La mano se distingue infinitamente, es decir, está separada por el abismo de una esencia diferente, de todos los órganos de prensión: dar zarpazos, arañar, apresar. Sólo un ser que habla, es decir, piensa, puede tener manos y en su manejo producir mano de obra. (...) la mano entrega y recibe, y no se reduce a hacerlo con cosas, sino que se da a sí misma a otros y se recibe de otros. La mano sostiene. La mano lleva. La mano diseña, y diseña seguramente porque el hombre es un signo.” M. Heidegger, ¿Qué significa pensar?, ed. cit., pp. 78-79.

${ }^{19}$ Met., A 2, 982b 20-21, trad. cit. 
tiene todo lo digno de admiración, todo lo maravilloso, hace que también "el que ama los mitos sea en cierto modo filósofo, pues el mito se compone de elementos maravillosos ( $\dot{\varepsilon} \kappa \theta \alpha v \mu \alpha \sigma i ́ \omega v)$ ". Ese elemento común tanto para la filosofía, pues en él encuentra su origen, como para el mito, pues se compone de esos elementos, es $\tau$ ò $\theta \alpha \tilde{u} \mu \alpha$ (lo que causa admiración, extrañeza, asombro). Algo acerca de lo cual nosotros no podemos decidir. Lo que nos asombra causa en nosotros un efecto del cual somos sujetos pacientes; propiciado, según Aristóteles, por el reconocimiento de una ignorancia que constituye nuestro tejido ontológico del modo más determinante. Hasta el punto de que quien pasa por ser uno de los héroes fundadores de la filosofía se presentaba a sí mismo como sabiendo que no sabía nada.

Habría pues un saber constitutivo de lo humano en cuanto humano, pero en forma negativa. Un saber que consistiría en reconocer la ignorancia que nos constituye y permite que experimentemos el asombro acerca de todo lo que es, desde lo más común hasta lo más complejo, originando la actividad filosófica que busca dar respuesta a ese estado de asombro que como una aporía condiciona nuestra existencia. Somos pues función de $\tau$ ò $\theta \alpha \tilde{v} \mu \alpha$, como algo que se nos impone desde una dimensión que trasciende lo natural experimentable, posibilitándolo pero quedando fuera de esa experiencia que Aristóteles en su historización de la filosofía identifica con los Jonios y con la causa material.

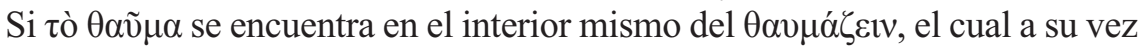
determina, según Platón y Aristóteles, el origen de la filosofía, lo es porque aquello que se nos impone como lo digno de asombro ( $\tau$ ò $\theta \alpha \tilde{v} \mu \alpha$ ) tiene que ver con la actividad filosófica por excelencia, la actividad que es precisamente función del quedar estupefacto: contemplar, considerar, examinar ( $\theta \varepsilon \alpha ́$ o $\mu \alpha \imath)$. Lo maravilloso y digno de asombro que dice $\tau$ ò $\theta \alpha \tilde{u} \mu \alpha$ tiene su correlato en la acción sensible e intelectual que desarrolla $\theta \varepsilon \alpha ́ o \mu \alpha r$ en cuyo interior se puede reconocer la presencia de $\theta \dot{\varepsilon} \alpha$, el acto mismo de mirar, de contemplar.

Toda esta puesta en relación de los términos griegos fundamentales relativos al $\theta \alpha v \mu \alpha ́ \zeta \varepsilon v v$, que según Platón y Aristóteles está en el origen mismo del filosofar, justifica las palabras de Heidegger cuando escribe "los griegos no han ilustrado la relación con el ente por medio del ver porque eran de "tipo visual" sino que, si se quiere emplear esa expresión, eran de "tipo visual" porque experimentaban el ser del ente como presencia y consistencia." ${ }^{20}$

${ }^{20}$ M. Heidegger, Nietzsche II, Destino, Barcelona, 2000, p. 182. En la misma línea que Heidegger, pero ahondando en las limitaciones de la ontología griega, F. Dastur escribe, “(...) l'étroitesse de l'ontologie grecque qui demeure une ontologie de la Vorhandenheit, c'est-à-dire de la présence déjà advenue, de la présenteté (Anwesenheit), et non pas de l'événement de la venue en présence (Anwesung). (...) l'ontologie antique, qui est une ontologie naïve (...)"Dire le temps. Esquisse d'une chrono-logie phénoménologique. Encre marine, La Versanne, 2002, p. 99. 
Si el admirarse y el quedar estupefacto está en el origen de la filosofía, lo está porque la filosofía para los griegos tiene que ver con $\tau$ ò $\theta \alpha \tilde{v} \mu \alpha$ por excelencia, con lo que en cuanto que da a ver es lo máximamente presencia en su ausencia presente y en cuanto que hace posible la visión $(\theta \dot{\varepsilon} \alpha)$ es la presencia misma que el ver no alcanza. Esta dimensión negativa, propia de lo que trasciende lo óntico por ontológico, justifica a su vez la ignorancia que le corresponde en términos epistemológicos referidos al conocimiento de una parcela específica de lo que es. La dimensión ontológica así como la negatividad epistemológica que corresponde a este admirarse originario constituye un primer elemento de respuesta al "ante qué" del quedarse estupefacto del principio, que Platón no supo o no quiso responder ${ }^{21}$ y que Aristóteles no terminó de formular, o al menos lo hizo condicionándolo a "lo que antiguamente y ahora y siempre se ha buscado y siempre ha sido objeto de duda." 22

Una vez identificado, tentativamente, el "ante qué" del asombro originario, arranque del filosofar, en la presencia y consistencia que constituye el ser del ente para los griegos, cabe preguntarse en qué consiste propiamente ese ser del ente que atraviesa toda la historia de la filosofía hasta nuestros días, y dónde o cómo localizarlo.

\section{Del ante qué del asombro, origen de la filosofia, a la lengua griega como destino del ser}

La palabra "ser", en castellano, remite inmediatamente en la mente del hablante al verbo homónimo sinónimo de existir, y por lo tanto, a todo lo que es en cuanto que existe, identificado con las cosas que son realidades materiales existentes y también, en menor medida, ideaciones o construcciones de la mente que aunque no existen realmente también son. En cualquier caso, la palabra "ser" despierta en el hablante hispanófono una cierta idea de realidad y de existencia que casa mal con la tesis que desde Heidegger en adelante parece imponerse en filosofía, al menos en el ámbito de la denominada "continental".

Una de las formulaciones más claras de lo que sería la conexión inextricable entre ser y lenguaje, queda enunciada en Introducción a la metafisica, y dice:

21 "Desde luego una obra mía referente a estas cuestiones ni existe ni existirá jamás (..) Pero yo no pienso que la llamada disquisición filosófica sea un bien para los hombres, excepción hecha de una escasa minoría de ellos que precisamente están capacitados para descubrir la verdad por sí mismos con un mínimo de iniciación” Carta VII 341 b- 342 b (trad. M. Toranzo), IEP, Madrid, 1970 , pp. 87-88.

${ }^{22}$ Met., VII, 1, 1028b 3-4 trad. cit. Ver P. Aubenque, Le problème de l'être chez Aristote, PUF, Paris, 1962, p. 250. Algo semejante quiere decir Platón cuando en el Sofista (246a) afirma por boca del Extranjero que "realmente parece que en estos hay una especie de lucha de gigantes que

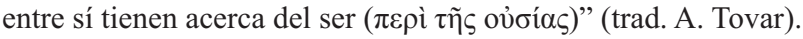


"Para nosotros, las cosas sólo llegan a ser y son en la palabra, en el lenguaje." 23 Según esta afirmación que Gadamer hará suya en la enunciación del principio hermenéutico por excelencia, "el ser que puede ser comprendido es lenguaje" 24 , lo que las cosas sean o devengan más allá del lenguaje nos es totalmente ajeno. El ser de las cosas se agota en la palabra, en el lenguaje. Esta tesis parece ir contra el sano sentido común para el que las palabras y el lenguaje son "cápsulas en las que las cosas se empaquetan para el comercio del que habla y escribe". ${ }^{25}$ Pero es sabido que el "sano sentido común", lo mejor repartido del mundo pues todos consideramos que tenemos suficiente según Descartes, no es el camino adecuado, al menos desde Parménides, para adentrarse en la problemática filosófica ${ }^{26}$. Considerar que por un lado van las cosas con su realidad material y su irreductible fisicalidad, y por otro las palabras y el lenguaje con su dimensión significante, y por ello siempre lista para el engaño, es una tesis que desde los sofistas viene proyectando una sombra retórica que protege del sol de la verdad. Por eso se trata de identificar y restituir la auténtica relación (den echten Bezug ${ }^{27}$ que el lenguaje mantiene con las cosas, con el fin de que dicha relación no se degrade en mera charlatanería y palabreo insignificante que nos llevaría a perder lo que más propiamente nos constituye en nuestro ser. Pues la humanidad del humano que somos se sostiene en una relación de respeto (reverencial) por la palabra y el lenguaje, máxima expresión del enigma que somos y del misterio que se extiende ante nosotros ${ }^{28}$. Sin embargo, la retórica que persigue el comprensible éxito en el ágora, donde el sol brilla con más fuerza, puede degradarse epistemológicamente en la búsqueda del beneficio que trae consigo el reconocimiento humano (sofística) y arrastrar consigo a la ontología de la ignorancia (Sócrates) para la que la rela-

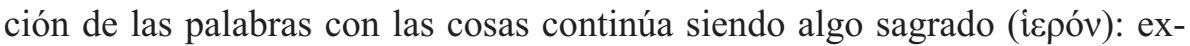

${ }^{23}$ M. Heidegger, Introducción a la metafísica, Nova, Buenos Aires, 1955, p. 52. "la palabra confiere a las cosas su ser" M. Heidegger, La esencia del habla, en De camino al habla, Serbal, Barcelona, 1987, p. 148.

${ }^{24}$ H.-G. Gadamer, op. cit., p. 567.

${ }^{25}$ M. Heidegger, Introducción a la metafísica (ed. cit.), p. 52.

${ }^{26}$ Fr. 6: “(...) Así que te aparté, lo primero, de esa vía de indagación,/y luego de esta otra que de cierto mortales que nada saben/se fabrican, bicéfalos, pues la incapacidad que hay en sus/pechos endereza un pensamiento descarriado. Y ellos se dejan arrastrar/sordos y ciegos a un tiempo, estupefactos, horda sin discernimiento/a quienes de ordinario ser y no ser les parece lo mismo/y no lo mismo y de todas las cosas es regresivo el camino." Parménides, Poema, Istmo, Madrid, 2007, pp. 23-25.

${ }^{27}$ M. Heidegger, Introducción a la metafísica (ed. cit.), p. 52.

28 "Porque el ser humano sólo lo es en la medida en que es prometido al decir confiador del habla; en que está puesto en uso y necesitado para el habla, para hablar el habla." M. Heidegger, La esencia del habla (ed. cit.), p. 176. 
presión del $\mu v \sigma \tau$ ṕpıv (lo secreto, lo oculto, lo cerrado) que hace que sólo el humano que somos esté en condiciones de reconocer la dimensión divina en todo lo que es en cuanto que es; dimensión transcendental del ser.

En estas condiciones de degradación lingüística, en lo que se refiere a la relación auténtica de las palabras y de las cosas, exacerbada por el proyecto consumista y nihilista propio de la cultura de masas desde hace casi un siglo, hay que distinguir al menos dos ámbitos: el socio-económico que marca históricamente (historisch) el acontecer de los humanos en el planeta y el lingüístico-ontológico que lo hace destinalmente (Geschick, Geschehen, Geschichte). Esta tesis se sostiene en una afirmación que aun reconociendo la dimensión específica de la lengua griega va más allá de lo que sería una tesis de índole meramente lingüística, pues supone, suposición que sólo puede ser demostrada filosóficamente, que "la lengua griega no es simplemente una lengua como las demás lenguas europeas que conocemos. La lengua griega, y solamente ella, es $\lambda$ ó $\gamma$ os. (...) en el caso de la lengua griega lo dicho en ella es, al mismo tiempo y de un modo señalado, aquello que lo dicho nombra. Cuando escuchamos una palabra griega en griego, seguimos su $\lambda \varepsilon ́ \gamma \varepsilon v v$, su modo directo e inmediato de mostrarse. La palabra muestra lo que está delante de nosotros. Gracias a la palabra escuchada ahora con oídos griegos, nos hallamos directamente en presencia de la cosa misma situada delante de nosotros y no frente a una pura expresión verbal." ${ }^{29}$

Es pues la dimensión lógica de la lengua griega la que posibilita que lo dicho en esa lengua, al mismo tiempo, nombre la cosa, haciendo que ésta se nos muestre en su ser y realizando así el principio fenomenológico "zur Sache selbst!'. Para Heidegger la diferencia entre la lengua griega y el resto de lenguas europeas radica en esta capacidad fenomenológica natural, propia sólo del griego escuchado con oídos griegos, por la que lo dicho en ella alcanza el poder nominador que hace que la cosa se nos presente en su propio $\operatorname{ser}^{30}$. Ahora bien, la posibilidad de acceder a este ámbito privilegiado de conocimiento pasa, entre otras cosas, por tener "oídos griegos" que nos permitan captar lo que la palabra contiene de nombre donde se revela el ser de la $\operatorname{cosa}^{31}$. Pues de eso se trata, de una comprensión del lenguaje en las antípodas de lo que la modernidad entiende por lenguaje, ya que

${ }^{29}$ M. Heidegger, ¿Qué es la filosofía? (ed. cit.), p. 42.

30 "Para Heidegger, en efecto, la fenomenología no es otra cosa que el método de toda filosofía, y, de modo particularmente especial, de la filosofía griega.” R. Brague, art. cit., p. 403.

${ }^{31}$ En "Douze questions posées à Jean Beaufret à porpos de Martin Heidegger" en 1975, el cuestionado explica cómo Heidegger, cuya lengua materna no era el griego, sino el alemán, logró no obstante dar cuenta del término aristotélico clave que es el de ousia. Y lo consiguió desde la acepción común de "bien de un campesino", a lo que en alemán le corresponde Anwesen, al cual a su vez hace brillar el femenino Anwensenheit, sinónimo de Gegenwart, lo presente que "habla -dice Beaufret- la lengua del tiempo". De modo que, concluye Beaufret, gracias a se- 
"la actual representación del lenguaje está lo más alejada posible de la experiencia griega del lenguaje. La esencia del lenguaje se manifiesta a los griegos como $\lambda$ ó ${ }^{\circ}$ c." $^{\prime 2}$ Mientras que en la contemporaneidad en la que Heidegger pronuncia su conferencia ¿Qué es la filosofía?, 1955, la comprensión (lingüística) que se tiene del lenguaje es mayoritariamente sígnica ${ }^{33} \mathrm{y}$ en gran parte estructuralista ${ }^{34}$. Pero la distinción entre ambas comprensiones no es equivalente, iguala una diferencia que Heidegger reivindica continuamente y que su albacea en Francia, Jean Beaufret, explicita del siguiente modo: “C'est en quoi pour les Grecs parler grec n'est pas faire usage d'une langue $(\gamma \lambda \tilde{\omega} \sigma \sigma \alpha)$, mais être pleinement eux-mêmes. A la différence des Européens d'aujourd'hui, leur langue ne leur était pas une langue mais une manière d'être." ${ }^{35}$ Quizá no todos los europeos sean iguales y sí haya hoy en Europa gentes para las que su lengua sea un "modo de ser". En todo caso, aquellos griegos vivían su lengua de una manera pre-sígnica, al menos en su sentido moderno, en la medida en que la dimensión lógica de la lengua griega les permitía asistir a la mostración de las cosas mismas ${ }^{36}$ como si de una fenomenología natural se tratase ${ }^{37}$. Heidegger era consciente en 1955 de que "no podemos regresar a esa esencia griega del lenguaje, ni podemos asumirla sin más. Muy al contrario, debemos establecer un diálogo con la experiencia griega del lenguaje en tanto que

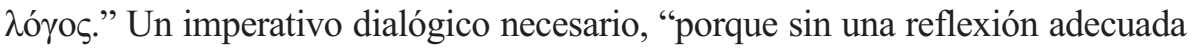
sobre el lenguaje jamás sabremos de verdad lo que es filosofía (...) como un modo privilegiado de decir." ${ }^{\prime 3}$

mejante diálogo, el griego ousia, "así aclarado y como revelado por lo que le responde de más próximo en otra lengua que no es el griego, pero fraternal con él, ya ha nombrado, casi sin darse cuenta, la temporalidad secreta del ser tal como se anuncia en un presente" op. cit., p. 22 (la trad. es mía). La clave pues del reclamado "oído griego" es un diálogo que desde la elección del sentido originario para ousia y su posterior traducción en alemán, concluye un sentido temporal para el término griego que éste en principio ignoraba poseer. Lo que puede confirmar esta filigrana etimológica es precisamente la dimensión participial de ousia, que esconde la ambigüedad nomino-verbal que caracteriza a todo participio.

${ }^{32}$ M. Heidegger, ¿Qué es la filosofía? (ed. cit.), p. 65.

${ }^{33}$ Ver Beaufret, Du logos au langage, en Dialogue avec Heidegger ***, Minuit, Paris, 1974.

${ }^{34}$ Ver P. Matthews, Breve historia de la lingüistica estructural, Akal, Madrid, 2009.

${ }^{35}$ J. Beaufret, op. cit., p. 83.

36 "En la gran época de los griegos, el signo (das Zeichen) se entiende sobre la base del mostrar (aus dem Zeigen) y viene acuñado sobre ésta a los fines del mostrar. Desde los tiempos del helenismo (Stoa) el signo procede de un fijamiento, se le decreta como el instrumento para una designación mediante la cual la representación está enfocada y dirigida de un objeto sobre otro objeto" M. Heidegger, El camino al habla, en De camino al habla (ed. cit.), p. 221.

37 "¿Qué es pensar a lo griego? (...) se trata de una investigación "fenomenológica” que tiene que llevar a la comprensión de lo que los griegos tienen de griegos. (...) ir de lo griego a lo más griego es ir de lo fenomenológico a lo más fenomenológico.” R. Brague, art.cit., p. 402.

${ }^{38}$ M. Heidegger, ¿Qué es la filosofia? (ed. cit.), p. 65. 
La lengua griega es para Heidegger, la lengua en la que "habla" el ser. Pues de otro modo no podríamos intentar escuchar su voz. ${ }^{39}$ Aún cuando esta afirmación suene extraña y el propio Heidegger pensaba unos años antes que "hemos perdido la capacidad de escuchar las pocas cosas simples dichas en las palabras de los pensadores iniciales" ${ }^{40}$, hay que darle la oportunidad de defender su sentido. Un sentido que si nos atenemos a lo dicho y a resultas de intentos fructuosos deberíamos poder oír. Pues escuchada su voz por fin accederíamos a la palabra del ser, y más aún a la polifonía que caracteriza a esa palabra en su ambigüedad fundamental. La del participio presente del verbo ser griego del que se derivará el hecho filosófico por excelencia en que consiste la diferencia ontológica, cuyo descubrimiento y tematización por parte de Heidegger viene condicionando el pensamiento desde hace casi un siglo. La diferencia ontológica va a permitir pensar más allá del positivismo que todo lo reduce a lo óntico, posibilitando una comprensión de la transcendencia del ser que desde la temporalidad constitutiva del Dasein a la espacialidad determinante del Ereignis, abre las puertas de la filosofía y con ella de la metafísica, hacia un pensamiento cada vez más consciente del $\tilde{\eta} \theta$ o $\varsigma$ que lo determina ${ }^{41}$.

\section{El destino del ser en su raíz participial o del sustrato lingüísto-lógico de la diferencia ontológica}

El relato acerca de la filosofía y de su surgimiento se ha hecho a menudo desde fuera de la filosofía misma, como si de la descripción de un paisaje en el que no se incluyera el narrador-espectador se tratara. Pero es evidente, hoy lo sabemos, al menos desde $\mathrm{Hegel}^{42}$, que quien pretende un relato acerca de la filosofía y su originariedad está dentro de la filosofía misma, al menos en el ámbito de la cultura occidental. No se puede pretender tener una perspectiva externa, como de mero testigo, de un acontecimiento del que necesariamente participamos, porque eso sería ignorar la raíz misma de aquello de lo que tratamos. Una raíz cuya lingüisto-logicidad ("la lengua griega, y solamente ella, es $\lambda$ ó $\varsigma_{\circ}$ ") se impone de manera necesaria, comprometiendo todo intento de comprensión del fenómeno filosófico y de su originariedad que no tenga en cuenta de manera determinante el fondo materio-lingüístico en el que germinará lo específico de la filosofía.

\footnotetext{
39 "Intentemos escuchar la voz del ser" Idem., p. 63

${ }^{40}$ M. Heidegger, Parménides (ed. cit.), p. 14

${ }^{41}$ Ver F. Duque, Heidegger y la ética originaria, en El segundo Heidegger: Ecología Arte Teología. En el 50 aniversario de Tiempo y Ser, Dykinson, Madrid, 2012.

42 "En efecto, Hegel es el que piensa por primera vez la filosofía de los griegos como un todo y ese todo filosóficamente" M. Heidegger, Hegel y los griegos en Hitos (ed. cit.), p. 346.
} 
En ese sentido apunta la afirmación de Heidegger cuando escribe, "la ambigüedad del ôv nombra tanto a lo que se presenta como a la presencia. Nombra a ambos al mismo tiempo y a ninguno como tal. (...) Si, tal como será necesario en el futuro, pensamos la esencia de la metafísica en el surgimiento de la duplicidad de lo que se presenta y la presencia a partir de la ambigüedad oculta del óv, entonces el comienzo de la metafísica coincidirá con el comienzo del pensamiento occidental. Si, por el contrario, tomamos como esencia de la metafísica la separación entre un mundo suprasensible y un mundo sensible, pasando aquél por ser lo verdaderamente ente mientras éste pasa por serlo sólo aparentemente, entonces la metafísica comienza con Sócrates y Platón. Ahora bien, lo que comienza con su pensamiento no es más que una interpretación expresamente orientada de esa inicial duplicidad en el óv. Con ella comienza el desacierto de la metafísica." 43

Acierto o desacierto, hay algo que más allá de las interpretaciones en una u otra dirección permanece como el lugar donde se esconde lo irreductible sustancial que justifica la posibilidad del filosofar mismo. Pues sin esa "ambigüedad oculta del ôv" que "nombra tanto a lo que se presenta como a la presencia", la razón ontológica sobre la que se sustenta tanto "el desacierto de la metafísica" como la posibilidad de un nuevo comienzo para el pensar, quedaría sin su material de construcción. Toda la verdad y la necesidad de las posibilidades de la filosofía radican en los vericuetos de la lengua donde se originó. Los filósofos son precisamente aquellos a los que a través de la escucha de lo que se dice en su lengua, en este caso la diferencia que se esconde en una forma verbal, se les ofrece una comprensión privilegiada de lo que denominamos "realidad". En palabras de J. Beaufret, "N'est-ce pas en fin dans ce participe ( $\mu \varepsilon \tau \odot \chi \eta)$ que nous avons à éprouver en quoi ces traditionnels amis du participe

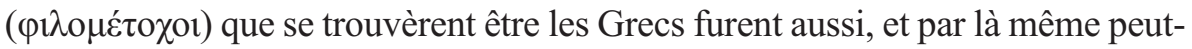
être, les véritables amis du savoir (

Ahora bien, no todos los mortales padecen, en cuanto filósofos, una comprensión participial de la "realidad"; la raza de los sofistas decide tener una comprensión interesada. En todo caso su voluntad de comprensión es función del interés y del provecho crematístico que puedan obtener del conocimiento.

${ }^{43}$ M. Heidegger, El concepto de experiencia de Hegel, en Caminos del bosque (ed. cit.), pp. 133-134.Comentando este pasaje de Heidegger, J. Beaufret escribe lo siguiente: "L'unité qui fait maintenant question, c'est donc jusque dans une pensée plus matinale que le platonisme et ce qui en provient que nous aurions pour tâche de la suivre à la trace. Mais d'autre part une telle pensée serait dans son essence l'ouverture d'une différence entre être et étant." Le destin de l'être et de la métaphysique, en Dialogue avec Heidegger ***, Minuit, Paris, 1974, pp. 13-14.

${ }^{44}$ J. Beaufret, Le Poème de Parménide, PUF, Paris, 1996, p. 34. 
En la ambigüedad oculta del participio presente del verbo ser en griego antiguo, en que consiste "la duplicidad de lo que se presenta y la presencia" se está nombrando el destino del contenido mismo del pensar filosófico, aun cuando "desde el inicio de la esencia de la metafísica permanece impensada la diferencia reinante en la ambigüedad del öv."

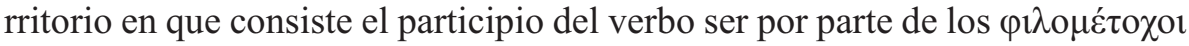
de la antigüedad griega, y especialmente por Parménides, su cartografía obvió la oculta ambigüedad constitutiva de tal forma verbal en beneficio de la dimensión meramente presente (nominal) que sin duda puede ser mucho más rentable gnoseológica y epistemológicamente que el tener que integrar en la descripción del nuevo territorio filosófico, la presencia que posibilita lo presente de lo presente (verbal) así como la diferencia misma entre ambas dimensiones. No cabe duda de que ese territorio hay que identificarlo con lo que Heidegger denomina "diferencia ontológica": no un producto mental fruto de especulaciones a la búsqueda de rarezas gnoseológicas sino el elemento determinante de una experiencia cognitiva que no sólo hacemos sino que fundamentalmente somos. ${ }^{46}$

\subsection{Breve incursión en el qué de la diferencia ontológica}

La diferencia entre ser y ente aparece desde las primeras páginas de Ser y tiempo (SZ) (1927). Pues Heidegger tiene claro que "el "ser" no puede ser concebido como un ente" ${ }^{47}$, y que "el ser del ente no "es" él mismo, un ente". ${ }^{48}$ La diferencia entre ser y ente, aunque no explicitada como concepto en $S Z$, es ya en esta obra el tópos trascendental ${ }^{49}$ donde se va a plantear la pregunta que constituye el corazón del pensar heideggeriano, la pregunta por el sentido del ser. Pues "el ser jamás es explicable por medio de entes ${ }^{a}$ ("Diferencia ontológica), sino que ser es siempre lo "trascendental" respecto de todo ente" ${ }^{50}$ Hay que señalar no obstante que tanto en el texto citado como al final de la primera sección de $S Z$, y según el Hüttenexemplar, aparece la expresión de "diferencia ontológica" como nota en este caso, a la pregunta acerca del significado del ser. "Qué significa que el ser "es", escribe Heidegger, cuando debe distinguírselo de todo ente ${ }^{a}$ ( ${ }^{a}$ Diferencia ontológica), sólo podrá ser preguntado concretamente

${ }^{45}$ Ibidem.

${ }^{46} \mathrm{Cf}$. S. Jollivet, De l'être au sens ou le « monde à l'envers ». L'émergence de la différence ontologique (1927/29), Philosophique, 9/2006, pp. 63-87.

${ }^{47}$ M. Heidegger, Ser y tiempo (trad. J. E. Rivera C), Introducción, cap. I, p. 27.

${ }^{48}$ Ibid., p. 29.

49 "Ser-escribe Heidegger- es lo transcendens por excelencia." Ibid., p. 61.

${ }^{50}$ Ibid., p. 229. 
una vez que se haya aclarado en general el sentido del ser y el alcance de la comprensión del ser". ${ }^{51}$

Sin embargo, la expresión de "diferencia ontológica" como tal no aparece en los textos hasta el curso del semestre de verano de 1927 impartido en la Universidad de Marburgo, recogido en Los problemas fundamentales de la fenomenología, donde Heidegger dedica el capítulo primero de la segunda parte a El problema de la diferencia ontológica. La expresión de "diferencia ontológica" quedará confirmada en las obras siguientes, Principios metafísicos de la lógica de 1928, donde Heidegger escribe, "llamamos diferencia ontológica a esta distinción que es la única que hace posible algo como la comprensión del ser. Con intención usamos la expresión neutral 'diferencia' porque precisamente el problema es en qué modo lo diferenciado en ella, ser y ente, se diferencia o diverge $^{52}$. Y se hace claro que con el problema de la diferencia ontológica se impone el problema originario del ser y el centro de la pregunta por el ser." ${ }^{53}$ También en De la esencia del fundamento de 1929, aparece ya la "diferencia de ser y ente (diferencia ontológica)" como el lugar de participación de la verdad óntica y la verdad ontológica. Diferencia que como no podía ser de otro modo, echa "las raíces de su propia posibilidad en el fundamento de la esencia del Dasein. Es a este fundamento de la diferencia ontológica al que, anticipándonos, llamamos la trascendencia del Dasein"54 que en ningún caso, como el propio Heidegger aclara en el Prefacio de 1949 a este mismo texto, "es el producto de una distinción del entendimiento (ens rationis)". ${ }^{55}$ Así, la diferencia ontológica es claramente función del Dasein en su aperturidad trascendental que posibilita el encuentro diferenciado de ser y ente, atendiendo tanto a la precomprensión constitutiva del ser por el Dasein como a la posibilidad histórica y finita de poder tener un discurso verdadero sobre los entes ${ }^{56}$.

${ }^{51}$ Ibid., p. 249.

${ }^{52}$ Quiero dejar constancia de que la definición que propone Aristóteles del concepto de "diferencia" ("Se dice que son "diferentes" aquellas cosas que son diversas, pero siendo lo mismo en algún aspecto, sólo que no numéricamente, sino según la especie o según el género o por analogía. Además, aquellas cuyo género es diverso, y también los contrarios, y también cuantas cosas comportan la diversidad en su entidad" [Metafísica, V, 9, 1018 ${ }^{\mathrm{a}}$ 12-15 (trad. T. Calvo)]), haría imposible el tratamiento que le da Heidegger oponiendo términos que nada tienen en común, como lo son los de ser y ente. Sólo desde la crítica heideggeriana al hecho de que ya en Aristóteles la impensabilidad de lo originario, en este caso la diferencia ontológica, está presente como metafísica justifica el uso para-aristotélico que hace del concepto de "diferencia" el de Messkirch.

${ }^{53}$ M. Heidegger, Principios metafísicos de la lógica, Síntesis, Madrid, 2009, pp. 178-179.

${ }^{54}$ M. Heidegger, De la esencia del fundamento, en Hitos, Alianza, Madrid, 2000, pp. 117-118.

${ }^{55}$ Ibid., p. 109.

${ }^{56}$ Ver J. Adrián Escudero, Heidegger y la genealogía de la pregunta por el ser. Herder, Barcelona, 2010, pp. 249-270. 
La evolución de este concepto irá pareja a la del pensamiento mismo de Heidegger, pues su pensamiento más propio no es otro que el pensamiento de la diferencia ontológica ${ }^{57}$, en cuanto ésta marca una diferencia irreductible con el resto de investigaciones y de ciencias. La esencialidad de esta diferencia radica en que es la más antigua, la que precede a toda diferencia, posibilitándola. Tal es la idea que se hace Heidegger de la diferencia ontológica en un texto del verano de 1931, dedicado a los capítulos 1, 2 y 3 del libro $\Theta$, de la Metafísica de Aristóteles, cuando escribe: “¿Qué es pues esta extraña diferenciación? Es la más antigua diferenciación, más antigua que ninguna otra. Pues cuando diferenciamos un ente de otro ente, esta más antigua diferenciación ya ha tenido lugar; sin ella todo ente aislado y toda diferencia a él referida quedarían ocultas. (...) Esta más antigua diferenciación, existe mucho antes que cualquier ciencia (...) Esta diferenciación del ente y del ser es tan antigua como el lenguaje, lo que quiere decir: tan vieja como el hombre. ${ }^{" 58}$

\section{Conclusión}

La diferencia ontológica tiene pues su base material en la ambigüedad oculta del participio őv, que tanto Parménides como Heráclito, tanto Platón como Aristóteles reconocieron como la cuestión misma del pensar ${ }^{59}$, pero cuya respuesta fue claramente insuficiente por no decir errada ${ }^{60}$. Una errancia que desde en-

${ }^{57}$ F. Dastur, Heidegger et la question du temps, PUF, Paris, 1990, p. 30 (Cfr. J. Adrián Escudero, Heidegger y la genealogía de la pregunta por el ser. Herder, Barcelona, 2010, p. 324).

${ }^{5}$ M. Heidegger, Aristote, Métaphysique $\Theta$ 1-3. De l'essence et de la réalité de la force [GA 33, 25] (trad. francesa de B. Stevens y P. Vandevelde) Gallimard, Paris, 1991, p. 33.

59 “A la diferencia originaria, que Parménides y Heráclito simplemente nombraron, Platón responde con el planteamiento de otra diferencia, pero esta vez no ya entre el ser y lo ente, sino una diferencia que queda enunciada entre « lo ente que es verdaderamente ente » (las ideas) y « lo ente que no es verdaderamente ente » (las cosas). Por medio de esta última diferencia, ha ocurrido lo siguiente : en primer lugar, se ha dado un olvido de la diferencia ontológica (la diferencia entre ser y ente), y en segundo lugar, se ha remitido la verdad a uno de los dos lados en que ahora está dividida la realidad, en concreto al lado de la idea, con lo cual se ha identificado la verdad con algo, a saber, con lo general y común, que ahora está más allá de lo físico, más allá de lo sensible : en lo suprasensible. » A. Leyte, Introducción en M. Heidegger, Identidad y diferencia [GA 11] (trad. H. Cortés y A. Leyte), Anthropos, Barcelona, 1988, p. 18.

60 "Les premiers penseurs grecs seraient par là les penseurs d'une telle différence qui après eux demeure bien présente mais n'a pas le tranchant décisif qui fut initialement le sien. C'est bien pourquoi, là où régnait sans réserve la différence, commence à poindre, étendant son ombre sur l'être, une préoccupation du suprêmement ou véritablement étant. Désormais la théologie égale et même dépasse le niveau du savoir encore anonyme de l'étant par où il est, bien qu'un tel savoir ne soit nullement aboli là où la théologie tend toutefois à conquérir la priorité. Mais celui-là n'est plus ontologique. La différence initiale devient ainsi différence ontologique" J. Beaufret, op. cit., p. 14. 
tonces condiciona la vida del humano en el planeta tierra pues nada está decidido para el hombre que éste no pueda pensar libremente ${ }^{61}$. En ese sentido lo decisivo es cómo planteamos, pues en eso consiste la actividad filosófica, la pregunta por el sentido del ser una vez que sabemos, primo, que la diferencia ontológica es el horizonte de todo pensar que aspira a superar la metafísica como respuesta errada al problema que plantea la ambigüedad oculta del őv de la que somos herederos y secundo, que la posibilidad de un nuevo comienzo en cuanto al pensar no es una utopía más a añadir al cúmulo del desastre en el que yace la memoria de los millones de asesinados en nombre del hombre nuevo, sino la honesta necesidad de, asumiendo la finitud constitutiva de lo humano, abrir el pensar a una diferencia cuyo reconocimiento posibilitará el inicio de la superación del dominio de lo óntico en todas sus versiones, teológicas y tecnocientíficas principalmente.

Ahora bien, lo que la ambigüedad del őv oculta es su doble dimensión, nominal y verbal, que como indica el nombre mismo de participio dice el hecho de que en esa forma verbal específica coexistan ambas formas gramaticales. Ocurre sin embargo que la decantación filosófica desde Platón en adelante ha favorecido la dimensión nominal del participio en detrimento de la verbal y por lo tanto temporal. Así desde aquellos inicios griegos "lo siendo" en cuanto "lo que es" se ha visto más identificado con su dimensión atemporal encarnada en algún ente supremo que con su posible dimensión temporal propia del sentido verbal que también es el suyo. "C'est précisément - escribe Françoise Dasturà cause de ce privilège reconnu au nom sur le verbe que la philosophie va être amenée dès le départ à s'orienter vers la recherche de formes séparés." ${ }^{\circ 2}$

Hoy que ya no ignoramos la dimensión errada de la metafísica, en su apuesta por un más allá sustancial y atemporal, y que tenemos a nuestro alcance los medios deconstructivos necesarios para desde la crítica orientar los nuevos

${ }^{61}$ El ejemplo más claro de esto es la tragedia griega. Para P. Szondi "la phrase qui constitue le fondement de toute la réflexion philosophique sur le problème du tragique : ç'avait été « une grande idée de consentir à subir le châtiment d'un crime inévitable, afin de manifester sa liberté par la perte de sa liberté même », on perçoit le motif sombre qu'ensuite aucune certitude du triomphe du sublime ne couvrira plus de sa voix, la conscience qu'une chose très haute a été détruite par cela même qui aurait dû la sauver » Le concept du tragique en Poésie et poétique de l'idéalisme allemand (trad. dirigida por J. Bollack) Minuit, Paris, 1975, pp. 11-12.

${ }^{62}$ F. Dastur, op. cit., p. 18. Curiosamente, un pensador francés a quien F. Dastur respeta profundamente, J. Beaufret, considera que es la dimensión verbal del participio la que va a triunfar en la tradición filosófica que se inaugura en aquel momento : «Cette double participation, au nominal et au verbal, de ce qui est à penser, mais avec prédominance du verbal sur le nominal, et qui prend son essor de ce verbe des verbes qu'est le verbe être, telle fut peut-être la plus ailée des pensées que formèrent les Grecs » La naissance de la philosophie, en Dialogue avec Heidegger *, Minuit, Paris, 1973, p. 28. 
caminos del pensar, no hacerlo sería insistir en una vía de pensamiento que obvia la diferencia en beneficio de un pensar totalizante a las órdenes de una voluntad capitalista que no atiende a medida, cuyas consecuencias irracionales en el siglo pasado deben estar absolutamente presentes para la memoria activa en este comienzo de siglo.

\section{BIBLIOGRAFÍA}

Adrián, J., Heidegger y la genealogía de la pregunta por el ser. Barcelona, Herder, 2010.

Aristotelis Opera, ex recensione I. Bekkeri ed. Academia Regia Borussica [1831], editio altera quam curavit Olof Gigon, Berolini apud W. de Gruyter, 1960.

Aristóteles, Metafísica (trad. V. García Yebra). Madrid, Gredos, 1982.

Aristóteles, Metafísica (trad. T. Calvo). Madrid, Gredos, 1994.

Aubenque, P., Le problème de l'être chez Aristote. Paris, PUF, 1962.

Beaufret, J., La naissance de la philosophie, en Dialogue avec Heidegger I. Paris, Minuit, 1973.

Beaufret, J., Dialogue avec Heidegger III. Paris, Minuit, 1974.

Beaufret, J., Le Poème de Parménide. Paris, PUF, 1996.

Beaufret, J., Douze questions posées à Jean Beaufret à propos de Martin Heidegger, por E. De Rubercy-D. Le Buhan. Pocket, Paris, 2011.

Brague, R., La fenomenología como vía de acceso al mundo griego, en Revista de Fi-

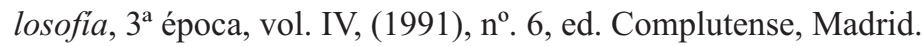

Dastur, F., Heidegger et la question du temps. Paris, PUF, 1990.

Dastur, F., Dire le temps. Esquisse d'une chrono-logie phénoménologique. La Versanne, Encre marine, 2002.

Deleuze, G., Nietzsche y la filosofia. Barcelona, Anagrama, 1986.

Duque, F., Heidegger y la ética originaria, en El segundo Heidegger: Ecología Arte Teología. En el 50 aniversario de Tiempo y Ser. Madrid, Dykinson, 2012.

Gadamer, H-G., Verdad y método I. Salamanca, Sígueme, 2005.

García Calvo, A., Razón común-Heraclito. Madrid, Lucina, 1985.

Heidegger, M., Ser y tiempo [GA, 2]. Madrid, Trotta, 2003.

Heidegger, M., Caminos del bosque [GA, 5]. Madrid, Alianza, 1998.

Heidegger, M., Nietzsche II [GA, 6.2]. Barcelona, Destino, 2000.

Heidegger, M., ¿Qué significa pensar? [GA, 8]. Madrid, Trotta, 2005.

Heidegger, M., Hitos [GA, 9]. Madrid, Alianza, 2000. 
Heidegger, M., ¿Qué es la filosofía? [GA, 11]. Barcelona, Herder, 2004.

Heidegger, M., Identidad y diferencia [GA, 11], Introducción por A. Leyte. Barcelona, Anthropos, 1988.

Heidegger, M., La esencia del habla, en De camino al habla [GA, 12]. Barcelona, Serbal, 1987.

Heidegger, M., Principios metafísicos de la lógica [GA, 26]. Madrid, Síntesis, 2009.

Heidegger, M., Aristote, Métaphysique $\Theta$ 1-3. De l'essence et de la réalité de la force [GA, 33]. Paris, Gallimard, 1991.

Heidegger, M., Introducción a la metafísica [GA, 40]. Buenos Aires, Nova, 1955.

Heidegger, M., Parménides [GA, 54]. Madrid, Akal, 2005.

Jollivet, S., De l'être au sens ou le "monde à l'envers ». L'émergence de la différence ontologique (1927/29). Philosophique, 9/2006

Matthews, P., Breve historia de la lingüistica estructural. Madrid, Akal, 2009.

Parménides, Poema. Madrid, Istmo, 2007.

Platonis Opera, ed. por J. Burnet. Oxford, Oxford University Press, 1900-1907.

Platón, Diálogos. Madrid, Gredos, 1981-2004.

Szondi, P., Le concept du tragique, en Poésie et poétique de l'idéalisme allemand. Paris, Minuit, 1975.

Vegetti, M., Platón. Madrid, Gredos, 2012. 